\title{
Method to estimate the medullar rays angle in pieces of wood based on tree-ring structure: Application to planks of Quercus petraea
}

\author{
Víctor Martínez-Martínez ${ }^{1, a}$, María del Alamo-Sanza ${ }^{2, a}$, María Menéndez-Miguélez ${ }^{1, a}$, \\ Ignacio Nevares ${ }^{1, a^{*}}$ \\ ${ }^{1}$ Departamento de Ingeniería Agroforestal, ${ }^{2}$ Departamento de Química Analítica, ${ }^{a}$ UVaMOX \\ Group, \\ Higher Tech. Col. of Agricultural Engineering, Universidad de Valladolid, Palencia, Spain, \\ *inevares@iaf.uva.es
}

\begin{abstract}
Estimating wood parameters employing non-destructive methods has been widely studied in recent years. The choice of wood used to build wine ageing barrels (cooperage) is strongly influenced by wood anatomy and specifically by the orientation of medullar rays among other aspects. In this article, a method based on the regularities of the tree-ring structure to estimate the medullar ray angle of the cross-section of a piece of wood is proposed. This angle shows the direction of the best linear path to evaluate several tree-ring features and could be employed to automate tasks, such as introducing an analysis path or rotating the image before the analysis, which some dendro analysis methods require. A dataset of 26992 synthetic images and 110 real oak wood images was used to validate the approach. The medullar ray angle of each image considered was measured manually and estimated using the method proposed here, which employs the Fast Fourier Transform (FFT) to take advantage of the tree-ring structure regularities and find the direction angle of the best linear path to evaluate several tree-ring features. The results obtained demonstrate a mean squared error of $0.29^{\circ}$ and $8.19^{\circ}$ and a mean absolute error of $0.19^{\circ}$ and a $5.91^{\circ}$ for the synthetic and oak wood images, respectively. These data suggest the suitability of the proposed method as part of an automated system to inspect and analyse the growth rings in oak wood planks.
\end{abstract}

\section{Introduction}

The economic and ecological value of trees is mainly based on the formation of wood and the accumulation of biocides, such as phenolic substances, which determine quality (Kampe and Magel 2013). Wood as a raw material has increased in significance over the last few years as one of the most important renewable resources for construction, bioenergy, wood-pulp for paper production, wood products, and as a carbon sink (Fromm 2013). To manage wood as the important resource it is and will continue to be in the future, it is fundamental to understand its structure, properties, and the process of wood formation.

During decades, researchers have studied the macro and micro structure of wood related to many different aspects, such as climate (Balducci et al. 2016; Bauwe et al. 2016), phenology (Deslauriers et al. 2008; Fernández et al. 2011), xylogenesis (Rossi et al. 2006; Camarero et al. 2010), wood quality (Larson 1969; Zobel and Buijtenen 1989), or physical and mechanical properties (Romagnoli et al. 2014). Many different programs and techniques were used to develop these studies. Traditionally, analysis of anatomical traits for wood identification is conducted using thin sections and light microscopy (Gartner and Schweingruber 2012). Some authors have proposed automatic methods to reduce or avoid human subjectivity in wood ring macroscopic analysis. For instance, Hietz proposed a program to measure ring width, identifying the latewoodearlywood transition, and detecting boundaries in conifers (Hietz 2011). This software analyses images to make its estimations but requires human assistance to prepare the samples and provide it with some information about these images. Another example is the work of Lara et al., which 
created a package in R statistical software (R Core Team) to measure tree-ring widths and identify ring borders from scanned images of wood (Lara et al. 2015). This software allowed automatic detection of the features considered, but still requires time-consuming sample preparation involving human assistance. The third example is the work of Van den Bulcke et al., who developed a 3D tree-ring analysis methodology based on helical X-ray tomography (Van den Bulcke et al. 2014). This method is automatic and improves upon the previous two methods because it works with 3D data. However, the usage of X-ray tomography data increases the acquisition and processing requirements in terms of time and money. Nevertheless, many of these techniques require laborious processes to prepare the samples prior to analysisanalys. In addition to the previously mentioned methods proposed in the scientific literature, there are several software applications which address this topic. For example, WinDENDRO (Regent Instruments Inc. - Quebec City, Canada) and CooRecorder (Cybis Elektronik \& Data AB - Saltsjöbaden, Sweden) allow the study of anatomical features and tree ring characteristics along a selected path, in an automated or semi-automated process. Nevertheless, these applications neither generate the path to analyse the samples automatically nor estimate the direction angle of the selected path.

Feuillat and Keller analysed several structural characteristics of oak wood, such as the ring width, the porosity, the earlywood width, and the number, width, and proportion of rays, in order to associate this information with barrel properties (Feuillat and Keller 1997). Bartens et al. evaluated the potential for dendro analysis of live oak (Quercus virginiana Mill.), concluding that the determination of wood structure variables in this type of wood is more difficult than in others (Bartens et al. 2012). The choice of wood used to build wine ageing barrels (cooperage) is primarily based on strength, flexibility and relative permeability to liquids (Feuillat and Keller 1997), properties strongly influenced by wood anatomy, with aspects such as the size of the vessels, the presence/abundance of tyloses, the proportion of spring/summer wood in the annual growth ring, the annual growth rate, or the orientation of medullar rays (Feuillat and Keller 1997; Guillaume de Pracomtal et al. 2014). Typically, the most decisive property is the annual growth rate, also known as grain, defined according to the anatomical features of the French oak wood (Feuillat et al. 1992). This is currently evaluatedby the cooper, who considers fine-grained wood, medium-grained wood, or coarse-grained wood when the distance between annual growth rings varies from 1 to $2 \mathrm{~mm}$, from 2 to $4 \mathrm{~mm}$, or greater than $4 \mathrm{~mm}$, respectively (Vivas 1995). Based on these criteria wine producers mainly choose between two species of oak: Quercus alba L. (American oak) or Quercus petraea (Matt) Liebl. (European oak), with the principal difference between these two species being the quantity of tyloses filling their vessels. The first has abundant tyloses, which allows the wood to be sawn and improves usage of the oak log. On the other hand, the presence of tyloses in European oak is lower than that in the American one, which necessitates splitting the logs to ensure liquid tightness of the wood.

The problem of estimating the orientation or the direction of the objects of an image has been previously addressed with different approaches: using the Hough transformation (Chaudhuri et al. 1993), estimating the skew angle of an image with a calibration method (Bian et al. 2013), analysing the two-dimensional (2D) FFT with Principal Component Analysis (Josso et al. 2005), and employing the photometric stereo technique (Zambal et al. 2015). Moreover, the 2D-FFT and the structure tensor of the image are also employed by OrientationJ and Directionality, which are two plugins of the ImageJ image processing software (ImageJ - National Institutes of Health USA)analys.

The main objective of this work was to propose a method to estimate the medullar ray angle of the cross-section of a log. This method is intended to be used to estimate the direction of the best linear path to analyse the image or the angle to rotate the image in order to dispose the rings in a vertical position, tasks that need another dendro analysis previously proposed in the literature. The main strength of this method is that it uses an image taken with a general purpose camera as the input to estimate the medullar ray angle, allowing automation of the acquisition process and the image processing procedure to measure tree-ring widths and identify ring borders from photos instead of scanned images of wood. Moreover, the structure of growth rings is considered in the method design. Finally, the proposed method has been evaluated using both a synthetic image 
representing a simplified model of the cross-section of a log and real Quercus petraea wood images. The obtained results suggest the suitability of the presented method as a prior step to automating other methods proposed in the literature to study the structure of wood.

\section{Materials and Methods}

\subsection{Oak wood samples}

The process of making barrels begins with first splitting the log to produce two half-short bolts. Next, the quarters are split into a several triangular sections, which are worked into planks by following the rift and grain of the wood. The squared timber is sawn to a thin length so that its face is perfectly flat and parallel to the grain. It is then re-sawn to obtain staves 25 or $31 \mathrm{~mm}$ thick (Fig. 1). For a detailed description of the process see the report of Seguin Moreau (Seguin Moreau Napa Cooperage 2016).

Once the rough staves are extracted, they are stacked outdoors in wood yards to allow seasoning, which is an essential stage for their subsequent treatment in cooperage. After this process, which takes between 18 and 24 months, rain and sun exposure reduce the phenolic compounds and create other modifications in the structure and composition of the wood that ease its handling in the cooperage.

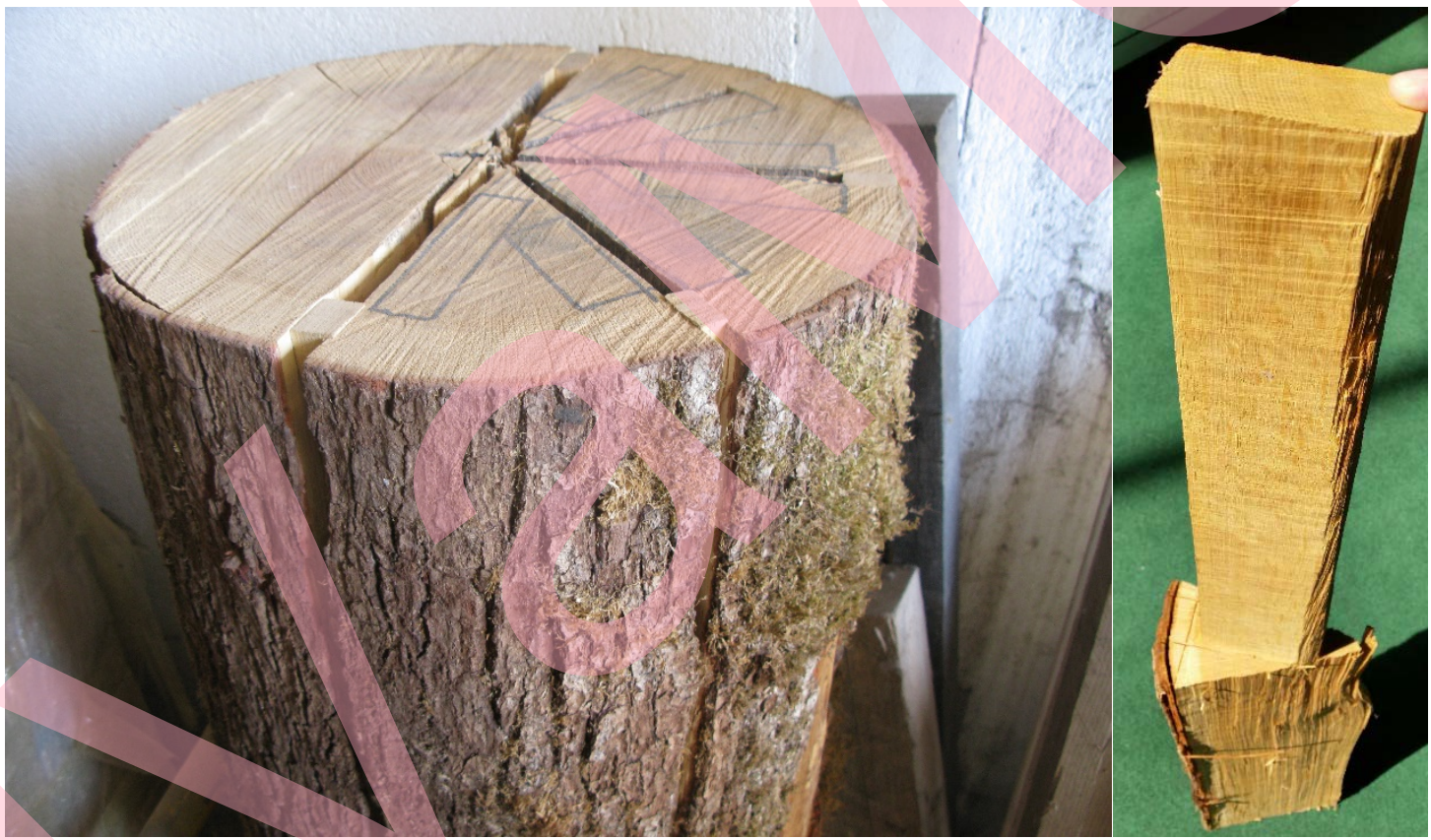

Fig. 1 Detail of a log of Quercus petraea in which the quarters are split into a series of triangular sections, in which the planks to be sawn can be seen. Detail of a triangular section from which a plank is sawn

The first step when the rough staves reach the cooperage is brushing. They are then classified according to their origin and the annual growth rate of the tree from which they were obtained, known as the grain (Feuillat et al. 1992). This classification process is very important because it establishes the composition of the wood that will age the wine and, related to that, the components that will be transferred during the ageing: aroma, phenolic compounds, etc.

In this study, pieces of Quercus petraea were split and worked into planks measuring 100x10x30 $\mathrm{mm}$ by following the rift and the medullar ray of the wood. These pieces were seasoned outdoors for two years and brushed before treatment in cooperage. A total of 56 raw staves were provided by Intona S.L. (Navarra, Spain). 


\subsection{Images}

Two image datasets were employed to evaluate the performance of the proposed method: a set of synthetic images and a set of real wood images.

\subsubsection{Synthetic images}

A set of synthetic images with different steering angles and other characteristics was employed to evaluate the proposed method in a controlled environment. The usage of synthetic images allowed for the elimination of the subjectivity of the measurement of the steering angle in real wood images and also reduced or suppressed the irregularities of their structure . Moreover, this makes it possible to evaluate the proposed method with images with the desired distance to pith and angle.

To generate the synthetic images employed in the experiments, a 3000x3000 pixel resolution image of a simplified model of a cross-section of a log, which is presented in Fig. 2, was employed. From this high resolution image, different angles and different distances to pith were considered when extracting the images to evaluate the proposed method.

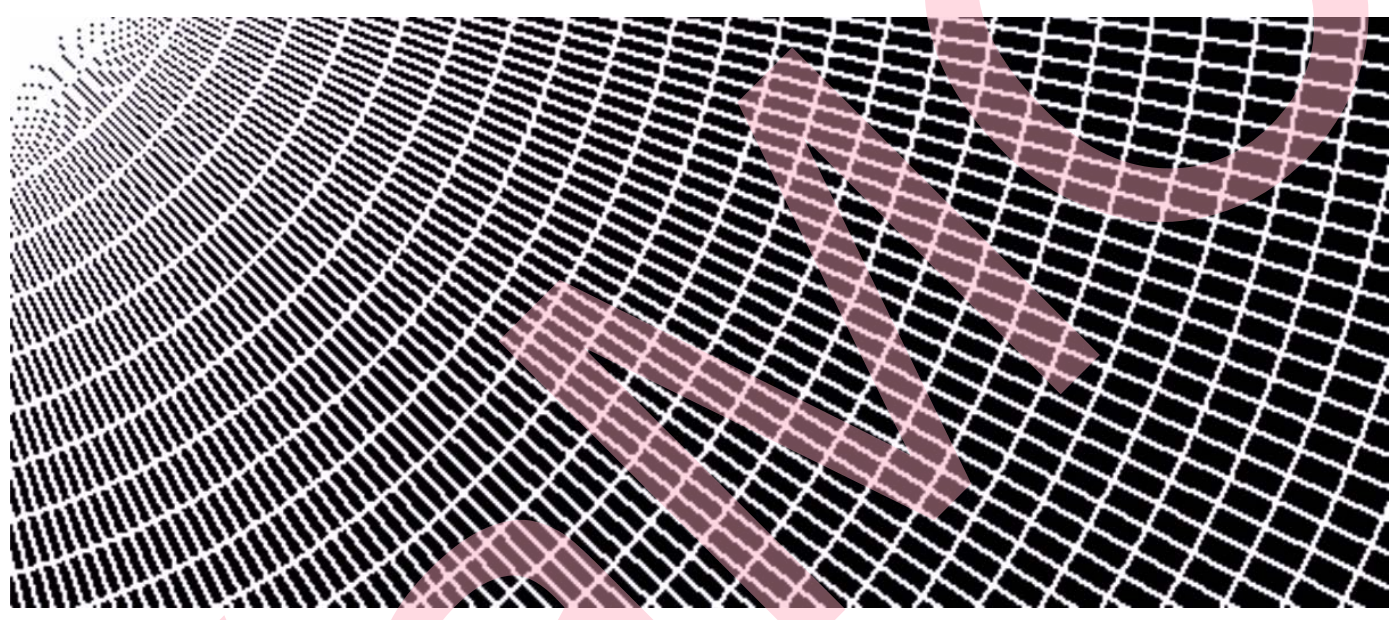

Fig. 2 Detail of the high-resolution synthetic image employed to extract images with different medullar ray angles and with different distances to the pith to evaluate the proposed method

As the synthetic image presented in Fig. 2 is a simple generic representation of the cross-section of a log and the separation between rings is uniform, the distances to pith in this image were measured in "rings". This allowed for evaluation of wood with different grains and homogeneous width rings, by means of translating the distance in the "rings" to the distance in mm using the rings per $\mathrm{mm}$ ratio to describe the grain.

\subsubsection{Real oak wood images}

Photographs of the cross-sections of the heads of the staves were acquired using a Panasonic Lumix DMC-FZ200 camera. The camera was placed $14 \mathrm{~cm}$ away from the analysed staves and a Fotima FTL-M232 macro LED ring was attached to it in order to illuminate the samples. A set of 110 images acquired from European oak staves was employed to evaluate the manual and the proposed method in real conditions. Fig. 3 presents six of the 110 images, showing the variability of the image dataset employed in this article. These images contained staves with different medullar ray angles (in Fig. 3(a) the medullar ray angle is approximately zero, whereas in Fig. 3(b) and Fig. 3(c) the medullar ray angle has a significant inclination and varies along the horizontal axis) with different distances to the pith (in Fig. 3(a) and Fig. 3(f) the staves were closer to the pith than in Fig. 3(b) and Fig. 3(d) staves) and with some surface defects (in Fig. 3(e) and Fig. 3(f) the staves had some surface cracks). 


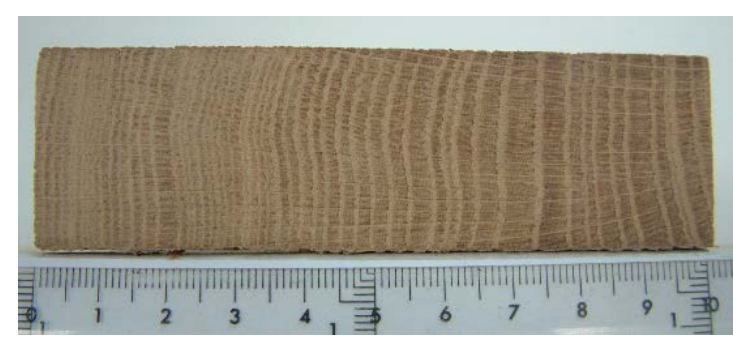

(a)

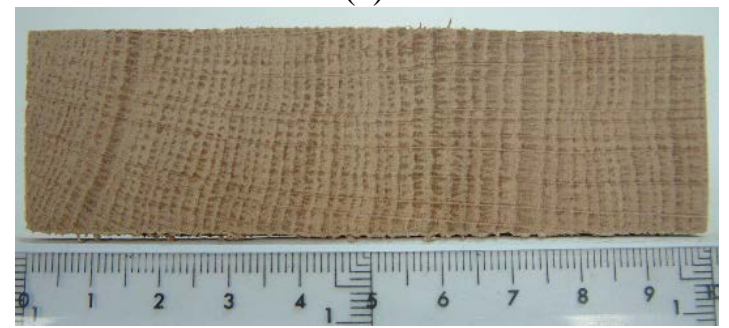

(c)

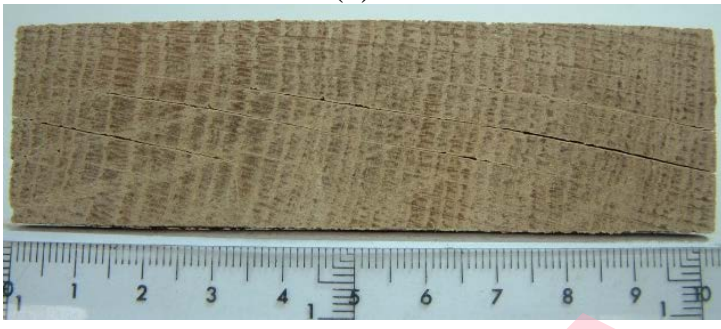

(e)

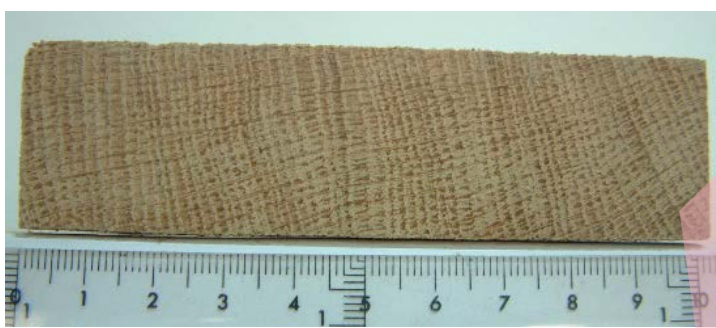

(b)

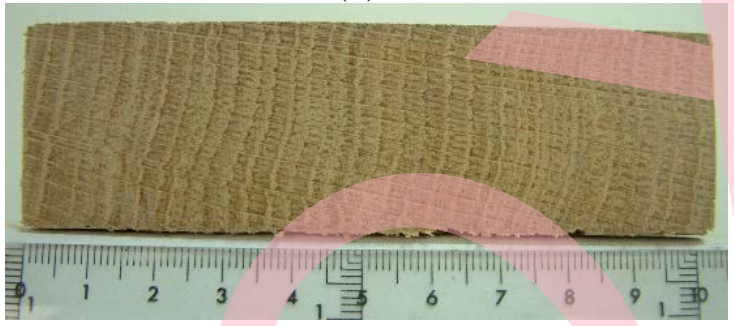

(d)

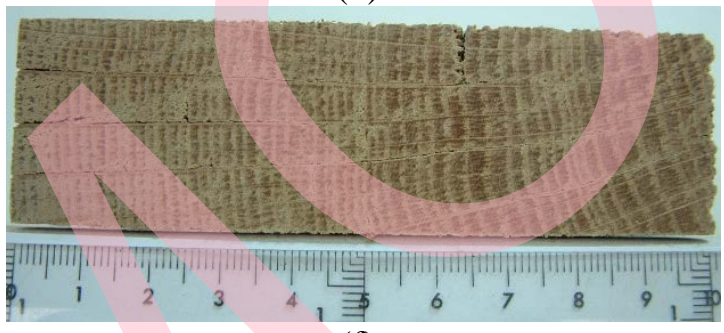

(f)

Fig. 3 Image of the cross section of six of the oak wood staves employed in the experiment. These six images expose the variability of the medullar rays' angle and the distance to the pith of the staves employed in the experiment. Moreover, subfigures (e) and (f) are examples of staves with surface defects that were also considered in the image database used in the article

\subsection{Medullar ray angle measurement. Manual method}

The angles of all the rays detected on each piece of wood were measured using the angle measurement software MB-Ruler (Markus Bader - MB-Software solutions - Iffezheim, Germany). The medullar ray angle was estimated as the mean value of the measured angles for each piece.

\subsection{Medullar ray angle measurement. Proposed method}

The method proposed in this article was implemented using the Matlab ${ }^{\circledR}$ computing environment (MathWorks - Massachusetts, USA) and consists of 3 stages, which are explained below. Fig. 4 represents a block diagram with these stages and the relationships among them:

Moreover, the pseudo-code that implements the proposed method represented in Fig. 4 is given in Online Resource 1. 


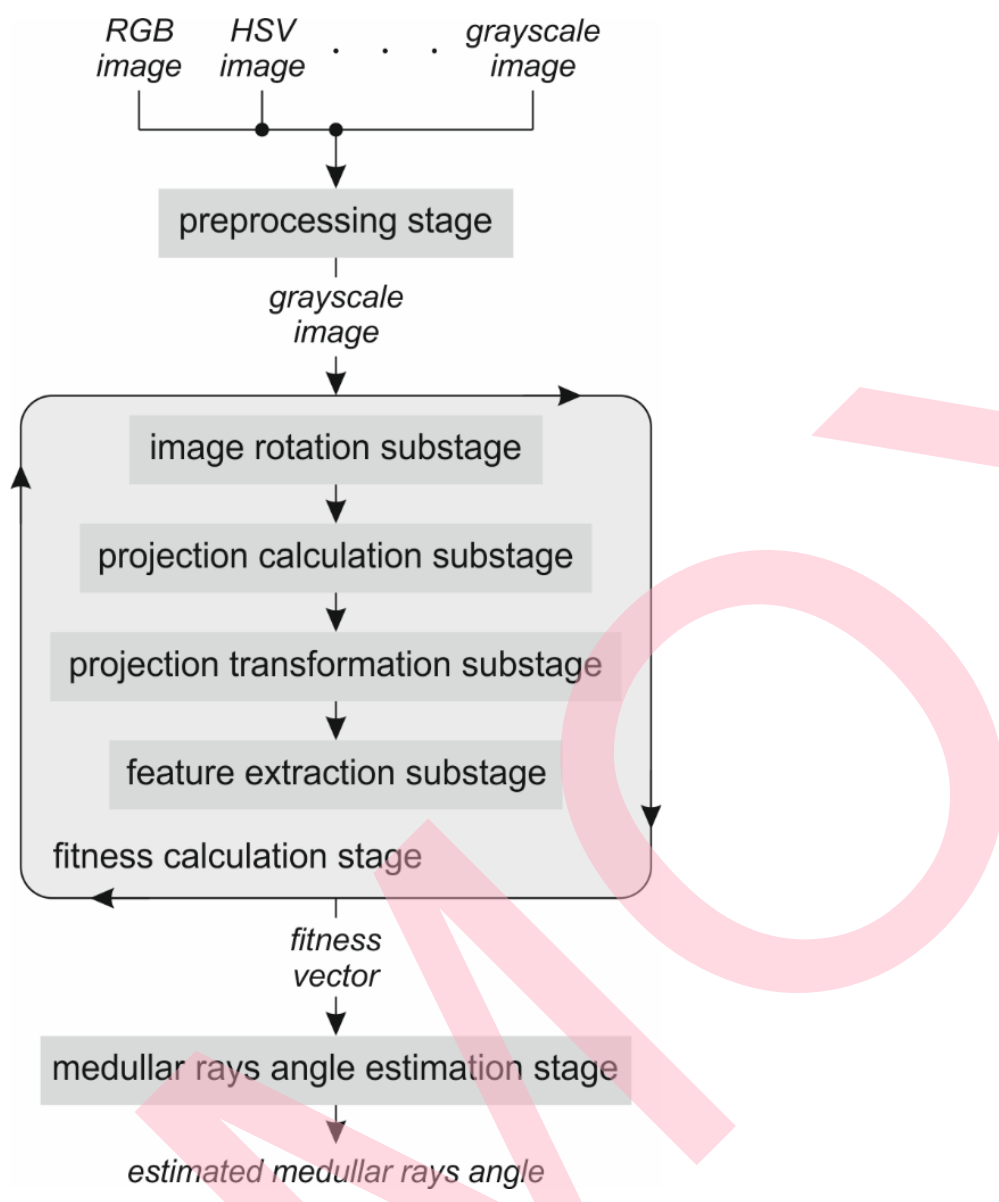

Fig. 4 Block diagram that represents the stages of the medullar ray angle method proposed in this work

\subsubsection{Preprocessing stage}

The preprocessing stage is only necessary for multichannel images (RGB, HSV, etc.) and it fuses the information of the different channels to obtain a grayscale image. In this article, where the real wood images employed were RGB images, the intensity of the image was considered as the grayscale image. Equation (1) presents the expression employed to obtain the intensity, where R, $\mathrm{G}$, and $\mathrm{B}$ are the red, green, and blue values of the image, respectively.

$$
\text { intensity }=0.29894 \cdot R+0.58704 \cdot G+0.11402 * B
$$

\subsubsection{Fitness calculation stage}

Once the grayscale image was obtained, the fitness calculation stage estimated a fitness value for each angle from a set of potential medullar ray angles of the analysed image. In this article, a vector of possible steering angles varying from $-90^{\circ}$ to $90^{\circ}$ with a resolution of $0.1^{\circ}$ was considered. The fitness value is directly related to the possibility that its associated steering angle is the real medullar ray angle of the image.

The fitness calculation stage can be divided into several substages: the image rotation substage, the projection calculation substage, the projection transformation substage, and the feature extraction substage. These substages are sequentially executed as many times as potential medullar ray angles are considered.

\subsubsection{Image rotation substage}


The image rotation substage consists of the rotation of the image around its centre point with a considered steering angle.

\subsubsection{Projection calculation substage}

This stage calculates the projection vector, which is a vector with the mean value of each row or column of the image. The rotated image was previously cropped to remove padding pixels added by the rotation procedure and to obtain projection vectors of the same length whatever the rotation angle in the previous substage was. This prune consisted of obtaining an $L x L$ image from the centre of the rotated image, where $L$ is expressed as represented in equation (2), and $W$ and $H$ are the width and height of the grayscale image, respectively.

$$
L=\frac{\min \{W, H\}}{\sqrt{2}}
$$

\subsubsection{Projection transformation substage}

After calculating the projection vector, it was first transformed into the Fourier domain using the FFT algorithm in order to analyse the periodicities of the projection.. The second power of the absolute value of the FFT vector, which is the energy spectral density, was then obtained. The result of this substage will henceforth be referred to as the transformed projection vector.

\subsubsection{Feature extraction substage}

The last substage of the fitness calculation stage is the feature extraction substage, which consists of extracting a characteristic value from the transformed projection vector that will represent the fitness value. In this article, five fitness values were considered: i) the energy of the signal (DC energy), that is, the integral of the transformed projection vector; ii) the energy of the projection vector without its DC component ( $A C$ energy), calculated as the integral of the transformed projection vector without considering the first element; iii) the maximum value of the transformed projection vector without considering the DC level, which is the first element of the transformed projection vector ( $\max A C$ ); iv) the crest factor (crest factor), which can be obtained as the ratio between max $A C$ and $D C$ energy; v) the value of the frequency at which the maximum value of the transformed projection vector without considering the DC level is reached ( $f$ max). Table 1 summarises the features considered.

\begin{tabular}{ccc}
\hline $\begin{array}{c}\text { feature } \\
\text { number }\end{array}$ & name & equation \\
\hline 1 & DC energy & feat_1 $=\sum_{n=1}^{N} P[n]$ \\
2 & AC energy & feat_2 $=\sum_{n=2}^{N} P[n]$ \\
3 & max AC & feat_3 $=\max \left\{\left.P[n]\right|_{n=2} ^{N}\right\}$ \\
4 & crest factor & feat_4 $=\frac{\text { feat_3 }}{f e a t \_1}$ \\
5 & fmax & feat_5 $5\left(f_{5}\right) \rightarrow f_{5} \in[2, N] / P\left[f_{5}\right]=\max \left\{\left.P[n]\right|_{n=2} ^{N}\right\}$ \\
\hline
\end{tabular}

Table 1 Summary table with the features employed in the proposed method and their equations

\subsubsection{Medullar ray angle estimation stage}

This stage uses the fitness vector, which contains the fitness values obtained for each steering angle considered, to determine the medullar ray angles in of the piece of wood. As previously mentioned, the fitness value has a direct relationship with the probability that a steering angle is 
the real medullar ray angle. Therefore, this stage selects the steering angle associated with the greatest fitness value as the estimated medullar ray angle.

\section{Results and discussion}

The results obtained after processing the synthetic and real images with the proposed method and the discussion after the analysis of these results are presented in this section. In the first part of this section, the synthetic images were employed to evaluate the performance of the proposed method in different conditions. In the second, the real European oak images were processed in order to estimate their medullar ray angles and compare them with the medullar ray angles measured manually.

\subsection{Method performance evaluation}

The performance of the proposed method was evaluated using images extracted from the synthetic image presented in Fig. 2. Those images had a resolution of 100x100 pixels, and were extracted varying the distance to pith of the tree and the medullar ray angle. This allowed for analysis of the possible variances in the precision of the proposed method in different working conditions.

To this end, 26992 images were extracted with a distance to pith varying from 4 to 1042.5 rings, a resolution of 0.5 rings and a medullar ray angle varying from $1^{\circ}$ to $89^{\circ}$ with a resolution of $1^{\circ}$ were employed to evaluate the proposed method. Moreover, the potential medullar ray angles used as steering angles in the fitness calculation stage of the proposed method varied from $-90^{\circ}$ to $90^{\circ}$ with a resolution of $0.1^{\circ}$. Fig. 5 and Table 2 present the outputs of the substages of the fitness calculation stage for an example image with a medullar ray angle of $27^{\circ}$ and a distance to pith of 25 rings. Fig. 5(a) shows the grayscale image, which was used as the input of the fitness calculation stage. Fig. 5(b) and Fig. 5(c) present the output of the image rotation substage, with the squared region used to obtain the projection vector highlighted, for two possible rotation angles: $27^{\circ}$, which is the real rotation angle, and $55^{\circ}$. The projection vector and the transformed projection vector of the two rotated images, which are the outputs of the projection calculation substage and the projection transformation substage, are presented in Fig. 5(d) and Fig. 5(e), respectively.

Finally, the estimated results of the feature extraction substage are presented in Table 2, where the features values for the image rotated $27^{\circ}$ (Fig. 5(b)) are seen to be higher than those for the image rotated $55^{\circ}$ (Fig. 5(c)), which suggests that the rotation angle of the first image is a better candidate to be the medullar ray angle than the rotation angle of the second image.

The correlation coefficient, the maximum absolute error, the mean absolute error, and the mean squared error obtained by the proposed method analysing the synthetic images are shown in Table 3 . These results were obtained discarding distances to pith lower than 20, because this region of the log is not used in cooperage since the minimum thickness of staves to build wine barrels is 20 $\mathrm{mm}$. The estimated results shown in Table 3 suggest that the best of the five features analysed (Table 1) is the AC energy.

\begin{tabular}{lcrrrc}
\hline & DC energy & AC energy & max AC & crest factor & f max \\
\hline image 1 & 708.7714 & 13.3192 & 1.4428 & $2.036 \cdot 10^{-3}$ & 3 \\
image 2 & 884.3000 & 492.8255 & 58.1070 & $6.571 \cdot 10^{-3}$ & 7 \\
\hline
\end{tabular}

Table 2 Output values of the feature extraction substage for the two images considered in Fig. 5 , rotated $27^{\circ}$ and $55^{\circ}$ respectively, and the five features considered. The fact that the value of the five features is greater for the image rotated $27^{\circ}$ suggests that this image is a better candidate for the correct orientation compared with the image rotated $55^{\circ}$ 


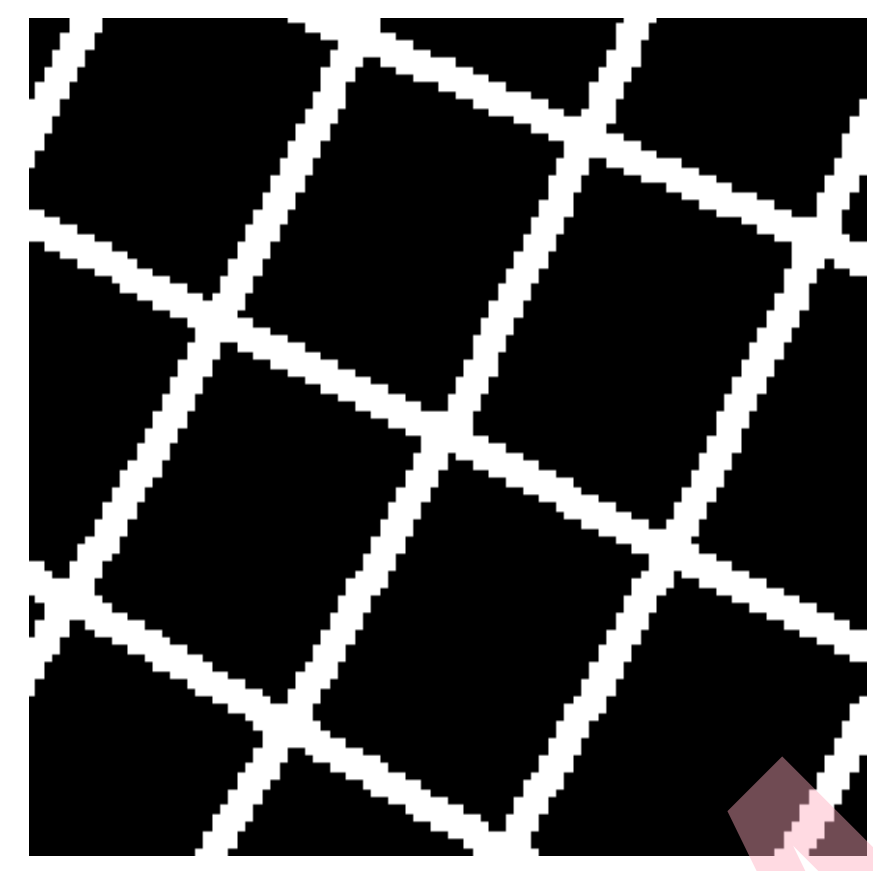

(a)

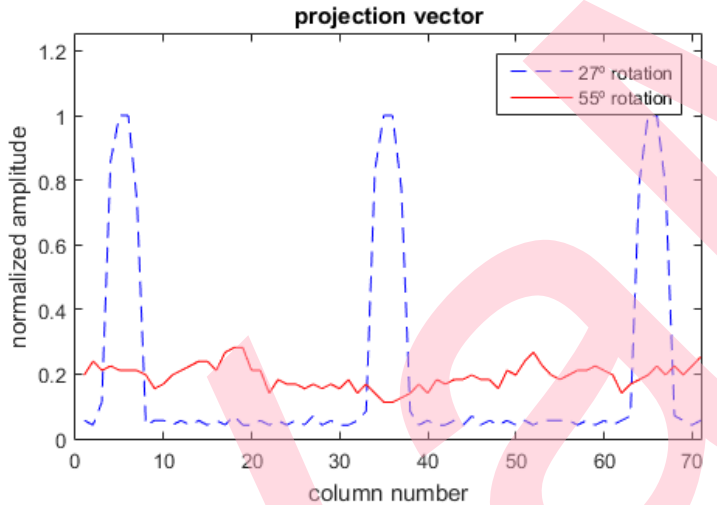

(d)

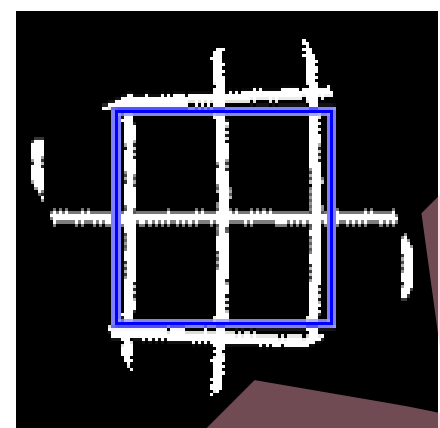

(b)

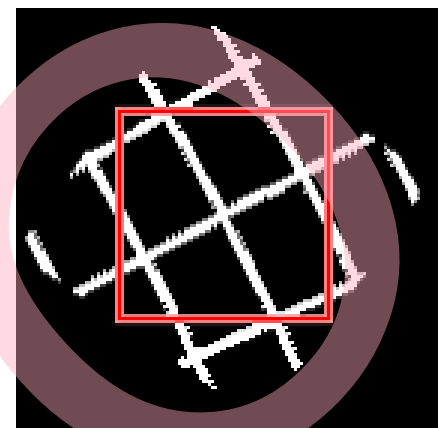

(c)

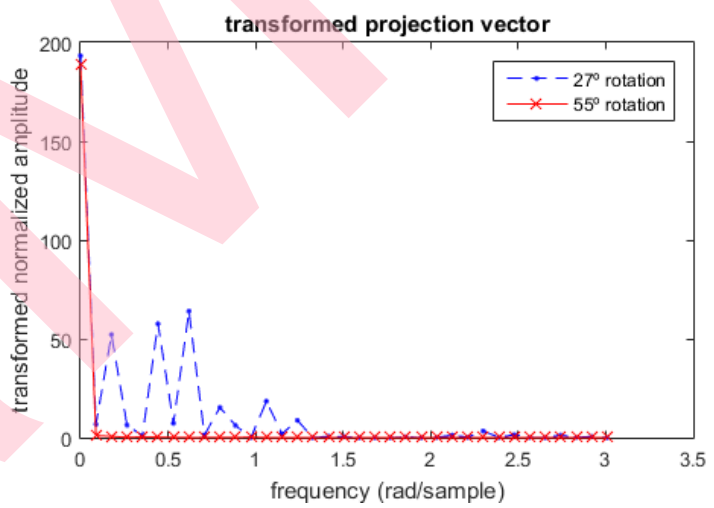

(e)

Fig. 5 Results of the substages of the fitness calculation stage for a synthetic image: (a) grayscale image used as input of the stage, with a medullar rays angle of $27^{\circ}$ and a distance to pith of 25 rings; (b) rotated image for a rotation angle of $27^{\circ}$; (c) rotated image for a rotation angle of $55^{\circ}$; (d) projection vector of the region highlighted in images (b) and (c); (e) transformed projection vector obtained from the projection vector presented in (d)

\begin{tabular}{lcccc}
\hline & $\begin{array}{c}\text { correlation } \\
\text { coefficient }\end{array}$ & $\begin{array}{c}\text { maximum } \\
\text { absolute error }\end{array}$ & $\begin{array}{c}\text { mean absolute } \\
\text { error }\end{array}$ & $\begin{array}{c}\text { mean squared } \\
\text { error }\end{array}$ \\
\hline DC energy & $99.988 \%$ & $2.80^{\circ}$ & $0.23^{\circ}$ & $0.35^{\circ}$ \\
AC energy & $99.992 \%$ & $2.00^{\circ}$ & $0.19^{\circ}$ & $0.29^{\circ}$ \\
max AC & $99.977 \%$ & $3.60^{\circ}$ & $0.33^{\circ}$ & $0.48^{\circ}$ \\
crest factor & $95.388 \%$ & $88.00^{\circ}$ & $3.27^{\circ}$ & $6.83^{\circ}$ \\
f max & $50.715 \%$ & $74.80^{\circ}$ & $33.66^{\circ}$ & $37.09^{\circ}$ \\
\hline
\end{tabular}

Table 3 Results of the medullar ray angles estimation using synthetic images for the five features considered 
After obtaining the error parameters shown in Table 3, the variance of the error with the medullar ray angle and the distance to pith was analysed, showing that the error is high when the distance to pith is close to 20 (the minimum distance to pith considered) and decreases when this distance increases, not having any visible dependence with the medullar ray angle. Fig. 6 presents the absolute error obtained versus the medullar ray angle and the distances to pith for the AC energy, which is the feature with the best results shown in Table 3 . This figure confirms this dependence for the $A C$ energy, with a decreasing error when the distance to pith increases, but always lower than $2^{\circ}$, and without any visual correlation between the absolute error value and the rotation angle.

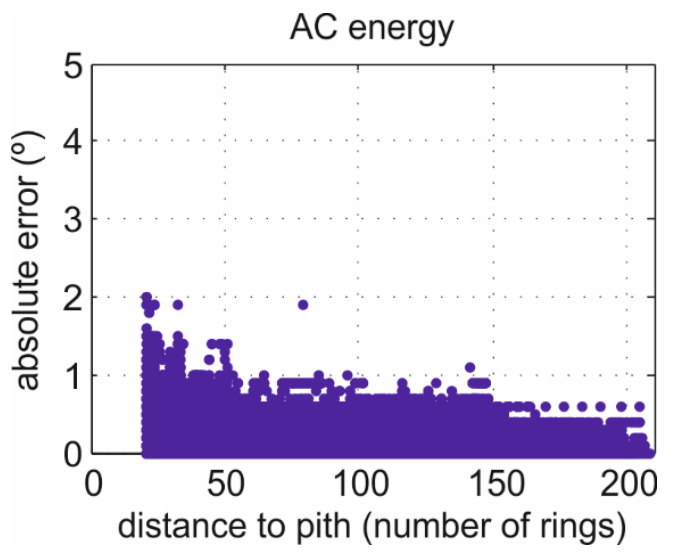

(a)

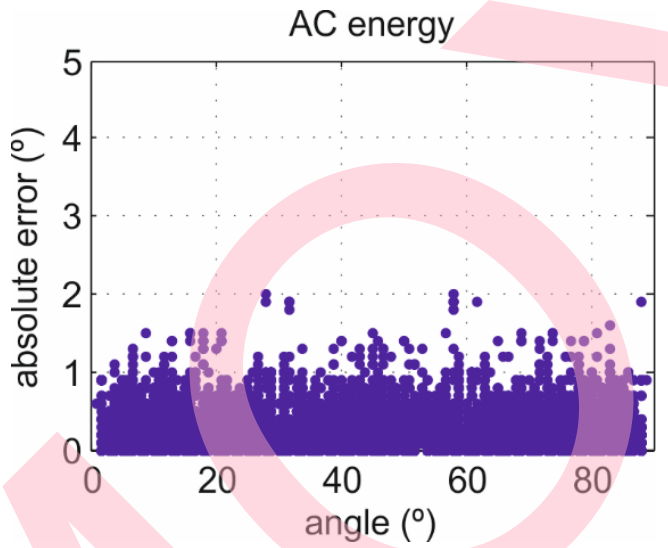

(b)

Fig. 6 Absolute error for the different medullar ray angles and distances to pith considered for the AC energy feature: (a) error obtained for the different "distance to pith" values; (b) error obtained for the different medullar ray angles. Images with a "distance to pith" lower than 20 were ignored because this region is not employed in cooperage

\subsection{Real oak wood medullar ray angle measurements and estimation}

The results obtained for each of the 110 images analysed are shown in Table 4, where the medullar ray angles were measured employing the MB-Ruler measuring angle software for each image presented. The medullar ray angles of the real pieces of wood analysed, varied from $-22.04^{\circ}$ to $20.27^{\circ}$. Table 4 also shows the estimated results obtained with the medullar ray angle proposed method considering the AC energy feature, which was the feature that obtained the best results with the synthetic images (Table 3).

Similarly to the results presented in Fig. 5 and Table 2 for an example synthetic image, Fig. 7 and Table 5 present the output of the substages of the fitness calculation stage for an example real image with a measured medullar ray angle of $19.6^{\circ}$. Fig. $7(a)$ represents the real grayscale image, which is the input of the proposed method. Fig. 7(b) and Fig. 7(c) show the output of the image rotation substage for a rotation angle of $19^{\circ}$ and $50^{\circ}$, respectively, with the squared region used to obtain the projection vector highlighted. The first angle $\left(19^{\circ}\right)$ was chosen because it is the real rotation angle, while the second $\left(50^{\circ}\right)$ was chosen as a candidate that is not the real solution. The projection vector and the transformed projection vector of the two rotated images, which are the outputs of the projection calculation substage and the projection transformation substage, are presented in Fig. 7(d) and Fig. 7(e) respectively. 


\begin{tabular}{|c|c|c|c|c|c|c|c|c|c|c|c|}
\hline $\mathrm{S}$ & $\mathrm{M}$ & $\mathrm{E}$ & s & $\mathrm{M}$ & $\mathrm{E}$ & $\mathrm{S}$ & $\mathrm{M}$ & E & $\mathrm{S}$ & $\mathrm{M}$ & $\mathrm{E}$ \\
\hline 1 & 8.62 & 12.5 & 2 & 3.83 & -6.0 & 3 & -8.70 & -1.5 & 4 & -8.79 & -14.5 \\
\hline 5 & 8.22 & 3.5 & 6 & -4.78 & 1.5 & 7 & -11.14 & -6.0 & 8 & -10.33 & -6.0 \\
\hline 9 & -7.82 & -11.0 & 10 & 7.19 & -6.5 & 11 & -10.20 & -14.0 & 12 & -8.53 & -14.0 \\
\hline 13 & -10.51 & -2.5 & 14 & 4.92 & 1.5 & 15 & 11.00 & 23.0 & 16 & -10.27 & -6.5 \\
\hline 17 & -12.66 & -12.5 & 18 & 16.87 & 26.0 & 19 & -18.73 & -14.0 & 20 & 7.09 & 0.5 \\
\hline 21 & -6.16 & -10.0 & 22 & -8.59 & -6.5 & 23 & 2.68 & -1.5 & 24 & -3.33 & -7.0 \\
\hline 25 & -11.09 & -1.0 & 26 & -11.74 & -15.0 & 27 & -14.93 & -6.5 & 28 & 6.04 & 10.0 \\
\hline 29 & -10.48 & 10.5 & 30 & -3.10 & 6.5 & 31 & 3.51 & 9.5 & 32 & 7.93 & 8.0 \\
\hline 33 & 6.50 & 0.0 & 34 & -22.04 & -1.0 & 35 & -10.56 & -19.5 & 36 & -19.63 & -17.5 \\
\hline 37 & -11.66 & -11.0 & 38 & 11.34 & 2.5 & 39 & 7.89 & 4.0 & 40 & -10.68 & -11.5 \\
\hline 41 & -8.44 & -9.0 & 42 & 11.85 & 4.5 & 43 & 7.99 & 10.5 & 44 & 11.66 & 24.0 \\
\hline 45 & -8.70 & -12.0 & 46 & 14.49 & 7.0 & 47 & -19.97 & -7.5 & 48 & 6.68 & -5.0 \\
\hline 49 & 8.78 & 5.0 & 50 & -10.40 & -3.5 & 51 & 4.92 & 6.5 & 52 & -5.99 & -7.5 \\
\hline 53 & -14.61 & 2.0 & 54 & 13.34 & 9.0 & 55 & 12.46 & 11.5 & 56 & -10.06 & -3.0 \\
\hline 57 & -12.90 & -10.0 & 58 & 6.84 & 8.5 & 59 & -10.19 & -1.0 & 60 & 12.04 & 6.5 \\
\hline 61 & 8.39 & -11.5 & 62 & 4.66 & 4.5 & 63 & 20.27 & 12.0 & 64 & -10.75 & -5.5 \\
\hline 65 & -7.00 & -5.0 & 66 & 11.19 & 12.5 & 67 & 11.37 & -1.0 & 68 & 11.11 & 8.5 \\
\hline 69 & -12.49 & -12.5 & 70 & 14.64 & 15.5 & 71 & 13.74 & 21.0 & 72 & -8.54 & -12.5 \\
\hline 73 & 9.81 & -1.0 & 74 & -8.81 & -6.5 & 75 & -11.68 & -11.5 & 76 & 6.29 & 5.5 \\
\hline 77 & 11.57 & 9.0 & 78 & 8.51 & 4.5 & 79 & -10.36 & -1.5 & 80 & 6.88 & 16.0 \\
\hline 81 & -8.03 & -6.5 & 82 & 5.89 & 3.5 & 83 & -14.17 & -3.0 & 84 & 6.27 & 4.0 \\
\hline 85 & 9.18 & -3.0 & 86 & -3.15 & -1.5 & 87 & 15.14 & 14.0 & 88 & -20.62 & -23.0 \\
\hline 89 & 7.36 & 8.5 & 90 & -12.43 & -15.0 & 91 & -13.94 & -4.5 & 92 & 11.09 & 4.0 \\
\hline 93 & -13.63 & -9.5 & 94 & -14.94 & -11.5 & 95 & -4.00 & -1.5 & 96 & -1.56 & -3.0 \\
\hline 97 & 18.82 & 2.0 & 98 & -18.75 & -11.0 & 99 & -13.12 & -10.5 & 100 & -15.86 & -17.0 \\
\hline 101 & 6.90 & 8.0 & 102 & -21.55 & 20.0 & 103 & -8.17 & -11.0 & 104 & 11.01 & 7.0 \\
\hline 105 & 17.23 & 12.0 & 106 & -8.27 & -7.5 & 107 & 5.74 & -5.0 & 108 & 7.66 & 4.0 \\
\hline 109 & 13.41 & 6.0 & 110 & 13.31 & 8.0 & & & & & & \\
\hline
\end{tabular}

Table 4 Medullar ray angle measured (M) and estimated with the AC energy feature (E) for the 110 real oak wood samples (s)

Finally, the estimated results of the feature extraction substage obtained after the process presented in Fig. 7 are presented in Table 5. The features values for the image rotated $19^{\circ}$ are seen to be higher than those for the image rotated $50^{\circ}$. This result suggests that the first rotation angle is a better candidate to be the medullar ray angle than the second one.

A summary of the results obtained comparing the five features presented in Table 1 with the angle measured employing the MB-Ruler measuring angle software is shown in Table 6. It presents the correlation coefficient, the maximum absolute error, the mean absolute error, and the mean squared error obtained comparing the analysed features with the angle measured. 


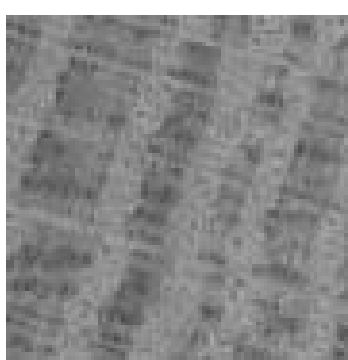

(a)

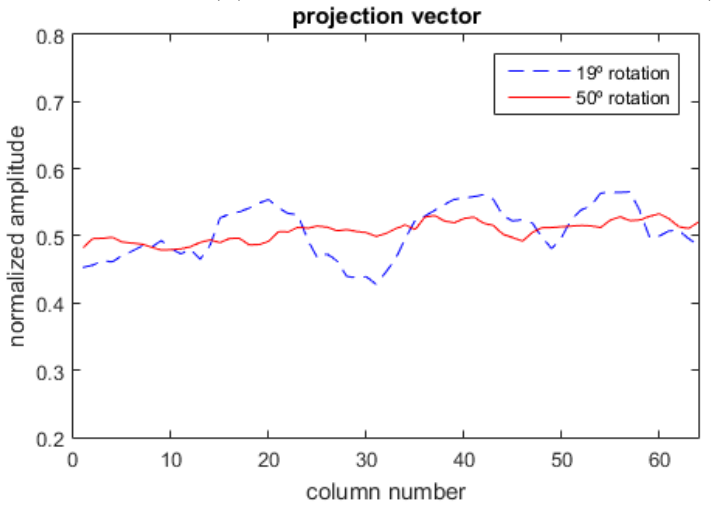

(d)

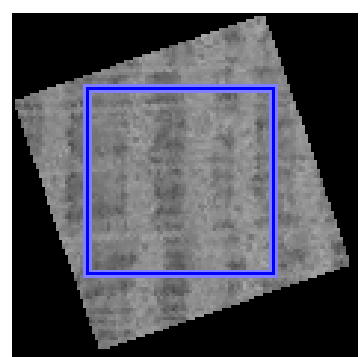

(b)

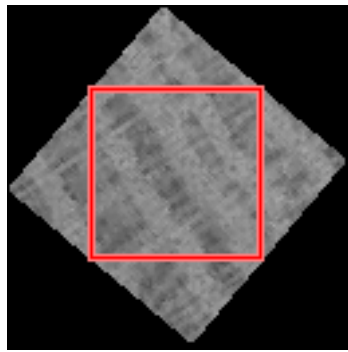

(c)

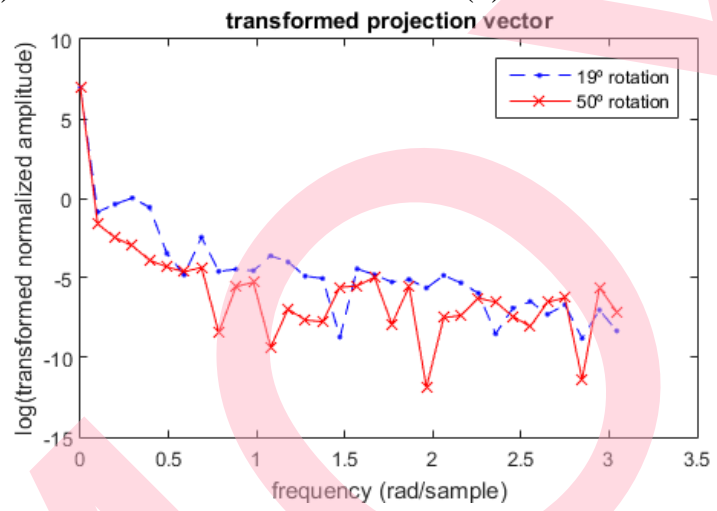

(e)

Fig. 7 Results of the substages of the fitness calculation stage for a real image: (a) real image used as input of the stage, with a medullar ray angle of $19.6^{\circ}$; (b) rotated image for a rotation angle of $19^{\circ}$; (c) rotated image for a rotation angle of $50^{\circ}$; (d) projection vector of the region highlighted in the images (b) and (c); (e) transformed projection vector, represented in a semilogarithmic graph, obtained from the projection vector presented in (d)

\begin{tabular}{ccccc}
\hline & $\begin{array}{c}\text { correlation } \\
\text { coefficient }\end{array}$ & $\begin{array}{c}\text { maximum } \\
\text { absolute error }\end{array}$ & $\begin{array}{c}\text { mean absolute } \\
\text { error }\end{array}$ & $\begin{array}{c}\text { mean squared } \\
\text { error }\end{array}$ \\
\hline DC energy & $11.51 \%$ & $60.97^{\circ}$ & $18.50^{\circ}$ & $24.43^{\circ}$ \\
AC energy & $70.90 \%$ & $41.55^{\circ}$ & $5.91^{\circ}$ & $8.19^{\circ}$ \\
max AC & $49.50 \%$ & $56.05^{\circ}$ & $8.21^{\circ}$ & $12.21^{\circ}$ \\
crest factor & $50.14 \%$ & 56.05 & $8.14^{\circ}$ & $12.16^{\circ}$ \\
f max & $18.54 \%$ & $60.36^{\circ}$ & $21.28^{\circ}$ & $25.67^{\circ}$ \\
\hline
\end{tabular}

Table 5 Output values of the feature extraction substage for the two images considered in Fig. 7 , rotated $19^{\circ}$ and $50^{\circ}$, respectively, and the five features considered. The fact that the value of the five features is greater for the image rotated $19^{\circ}$ suggests that this image is a better candidate for the correct orientation compared with that rotated $50^{\circ}$

\begin{tabular}{lcccc}
\hline & $\begin{array}{c}\text { correlation } \\
\text { coefficient }\end{array}$ & $\begin{array}{c}\text { maximum } \\
\text { absolute error }\end{array}$ & $\begin{array}{c}\text { mean absolute } \\
\text { error }\end{array}$ & $\begin{array}{c}\text { mean squared } \\
\text { error }\end{array}$ \\
\hline DC energy & $8.40 \%$ & $60.97^{\circ}$ & $18.57^{\circ}$ & $24.28^{\circ}$ \\
AC energy & $76.61 \%$ & $21.04^{\circ}$ & $5.60^{\circ}$ & $7.21^{\circ}$ \\
max AC & $56.43 \%$ & $49.22^{\circ}$ & $7.91^{\circ}$ & $11.23^{\circ}$ \\
crest factor & $57.14 \%$ & $49.22^{\circ}$ & $7.84^{\circ}$ & $11.17^{\circ}$ \\
fmax & $18.37 \%$ & $60.36^{\circ}$ & $21.12^{\circ}$ & $25.51^{\circ}$ \\
\hline
\end{tabular}

Table 6 Relationship between the estimation results obtained with the proposed method and the medullar ray angles measured for the 110 images analysed in this article. The correlation coefficient, the maximum absolute error, the mean absolute error, and the mean squared error were calculated for each of the five features employed in the proposed method 
As previously mentioned, estimated results obtained both with the synthetic and the real wood images suggest that the best of the five features analysed (Table 1 ) is the AC energy, as seen in Table 3 and Table 6. It is interesting to note the ease to calculate the features proposed in this article, which, combined with the low processing requirements of the stages of the proposed method, allow its implementation on a production line. In the experiments performed here the time needed forthis method was $800 \mathrm{~ms}$ to $1000 \mathrm{~ms}$. It is also worth mentioning that the proposed method can be redefined when AC energy is the feature employed, because it is possible to obtain the AC energy of the FFT of a signal without calculating its FFT. It allows the complexity of the method to be reduced and thus its processing time requirements.

The relationship between the absolute error and the medullar ray angle for the real wood is shown in Fig. 8, with the absolute error versus the medullar ray angles measured employing the MBRuler measuring angle software for the real wood images represented. Results presented in this figure agree with those shown in Fig. 6 for the synthetic images, suggesting that the error of the proposed method does not have any relationship with the medullar ray angle. The distance to pith invariance shown in Fig. 6(b) cannot be certified with the real wood images because this measurement was not available for the pieces of wood analysed.

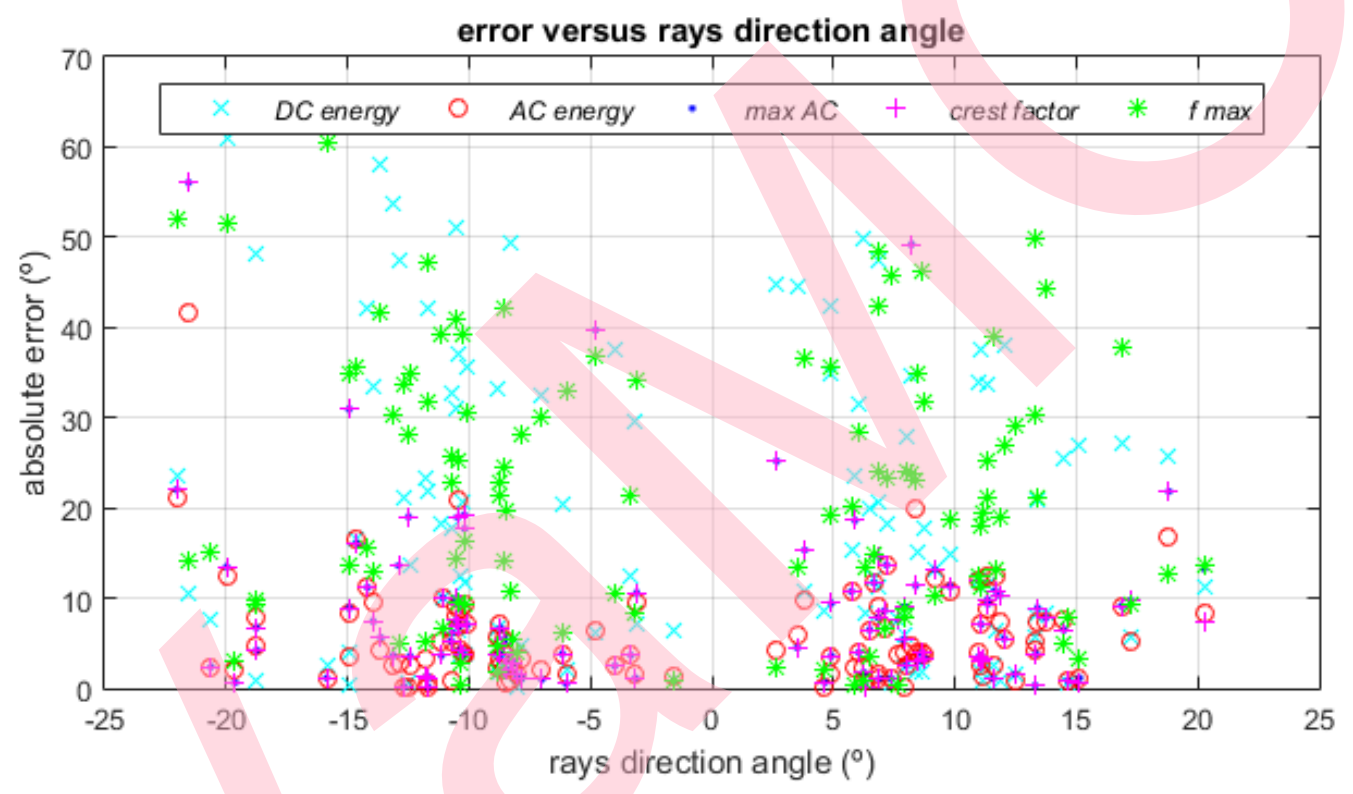

Fig. 8 Distribution of the absolute error obtained for the different features employed in the proposed method to determine medullar ray angles in the real wood images analysed in this article

A visual example of the performance of the proposed method with four real wood images is presented in Fig. 9. Each subfigure shows the original image with the analysed ROI squared in green, the original ROI, and the ROI rotated angle estimated by the proposed method using the AC energy feature at the top, the bottom-left, and the bottom-right of the subfigure. 


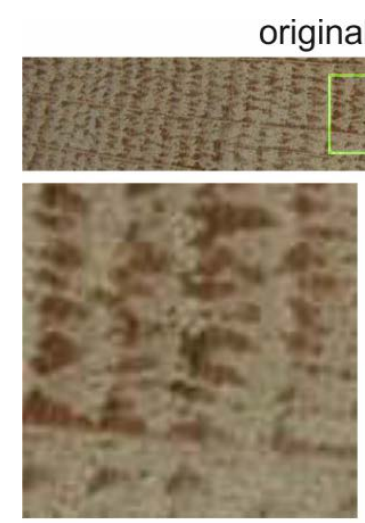

original $\mathrm{ROI}$

(a)

original image

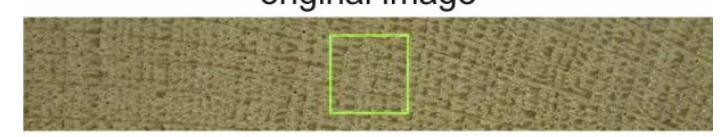

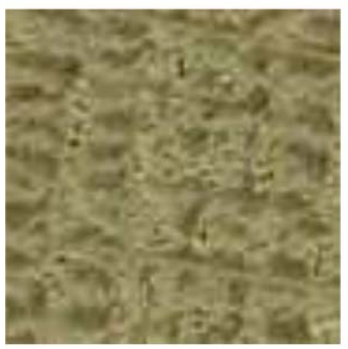

original $\mathrm{ROI}$

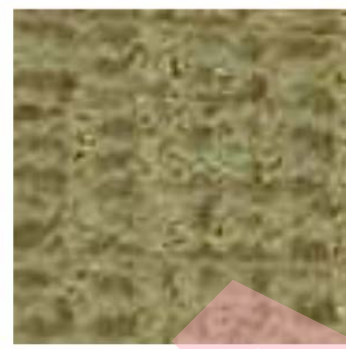

rotated ROI (c)

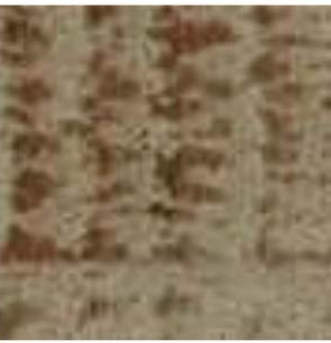

rotated ROI

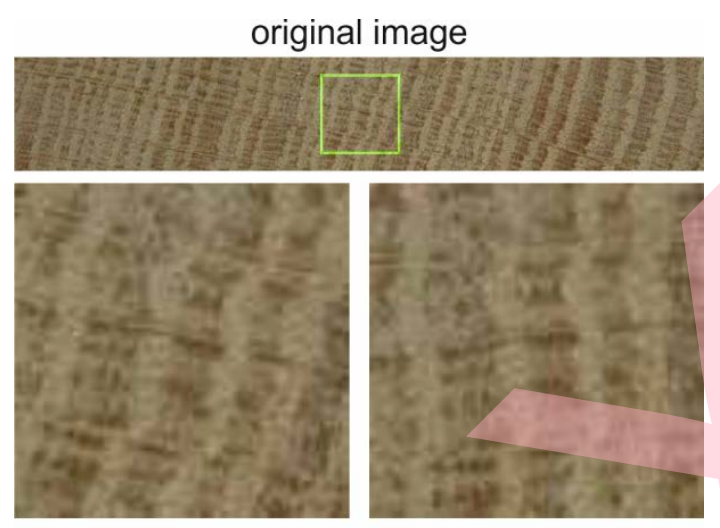

original $\mathrm{ROI}$ rotated ROI

(b)

original image

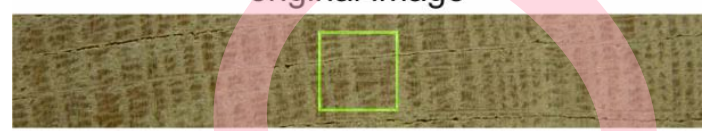

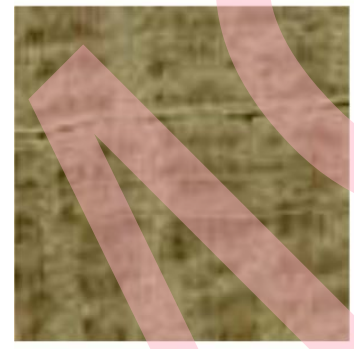

original ROI

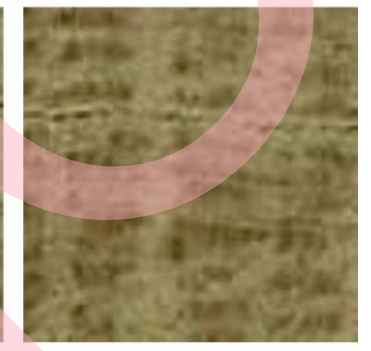

rotated ROI (d)

Fig. 9 Example of the method performance for the samples 7 (a), 35 (b), 47 (c), and 101 (d). Each subfigure presents the original image with the analysed ROI squared in the top image, the original ROI, and the ROI rotated, the angle estimated by the proposed method using the AC energy feature at the top, the bottom-left, and the bottom-right of the subfigure

It is interesting to note that the proposed method aimed to estimate the medullar ray angle of a piece of wood, that is, to estimate the angle of the medullar rays to the horizontal axis. Nevertheless, due to the theoretical anatomical structure of the wood, this objective is equivalent to that of finding the direction of the linear path that perpendicularly crosses the growth rings. On the one hand, this angle will be useful for several semi-automated methods that need the user to introduce a path, because it will allow the process of generating this path to be automated. Some examples of this methods are those proposed by Hietz (Hietz 2011) or the methods implemented by WinDENDRO or CooRecorder.. On the other hand, the estimated angle will be useful for methods like that designed by Lara et al. (Lara et al. 2015), which needs to have the growth rings in a vertical or horizontal orientation It is interesting to note that the proposed method is able to align the growth rings in a vertical position, which is equivalent to estimating the angle of the linear path that perpendicularly crosses the growth rings, even in the pieces of wood with a significant estimation error. For example, Fig. 9(b) shows the growth rings in a vertical position, despite a medullar ray angle estimation error of $8.94^{\circ}$. The reason why this method was proposed to estimate the medullar ray angle instead of the growth ring angle is due to the difficulty involved in designing a reliable, replicable, and systematic manual method to measure the growth ring angle, which is necessary to evaluate the performance of the proposed method.

Fig. 3 and Fig. 9 illustrate the variability of the different images of the wood considered, where different grain, different rotation angles, and different distance to pith values are seen. Other 
variables were also observed among these images where it is difficult to view the rays of the wood, images with and without visible vessels, or different colour values for the earlywood and the latewood, due to internal structure (Plomion et al. 2001; García Esteban et al. 2003). Earlywood vessel variables are well known to depend on climate conditions, especially precipitation (Hroš and Vavrčík 2014). This variability among the images analysed suggests that the proposed method is robust and will work properly for other modifications.

Finally, it is noteworthy to mention that the results presented in Table 6 were obtained considering the 110 images analysed in the article. Nevertheless, as can be observed in Fig. 3 and Fig. 9, there are several pieces that have defects that can affect the performance of the proposed method. Table 7 presents the results obtained removing the 11 images of the real oak wood image dataset that have surface cracks and other defects.

\subsection{Results comparison and general analysis}

The main observation that can be extracted comparing the results is that the errors obtained for the real oak wood images are greater than those obtained for the synthetic images. One explanation for this is the regularity and absence of noise in the synthetic images, which makes them more similar to the theoretical structure of the cross-section of a piece of wood. As the proposed method is based on the regularities and the repeatability of the structure of the crosssection of a piece of wood, the absence of irregularities and non-ideal structures in the synthetic images explains the low error obtained with these compared to those obtained with the real ones. Another reason to justify this difference is the subjectivity of the measurements of the medullar ray angles in the real wood images. For this reason, the angle considered as real for each piece of wood can be expected to vary if another person measures it or if the medullar ray angle is estimated using another method (for example, considering the middle of the piece instead of its extremes).

Despite the fact that the performance results for the real wood images were worse than those obtained for the synthetic ones, the same conclusions can be extracted from both analyses: the comparison concerning the five features analysed is similar, as the AC energy feature was the best one, and the worst was $f \max$ which can be observed in Table 3 and in Table 6 and Table 7, respectively. In addition, the invariance of the errors with the medullar ray angles of the analysed images was verified for both the synthetic images and the real ones in Fig. 6 and Fig. 8,, respectively. This aspect suggests that the synthetic image designed to model the cross-section of a log and employed to evaluate the proposed method is representative, and the estimated results obtained with it are significant and can be employed to extract conclusions. Moreover, the proposed method is expected to be almost invariant with the distance to pith of the image, as can be observed in Fig. 6 for the synthetic images. Nevertheless, it cannot be checked for the real images because this variable was not measured in the oak staves.

The proposed method can be employed as a previous stage of several wood structure analysis methods that perform the analysis over a path adjusted by the user, such as the proposal of Hietz (Hietz 2011) or the methods implemented by WinDENDRO or CooRecorder. It can also be useful for methods that need to know the angle of the growth rings to generate an input image with a specific position, such as that proposed by Lara et al. (Lara et al. 2015), or to estimate the distance among rings, such as in the work of Van den Bulcke et al. (Van den Bulcke et al. 2014). The method presented in this article was evaluated employing Quercus petraea wood, which is that used to build barrels for the ageing of wines in cooperage. Even taking into account the possible difficulties in the analysis of oak wood structure, as shown by Bartens et al. for Quercus virginiana (Bartens et al. 2012) and Haneca et al. for Q. robur and Q. petraea (Haneca et al. 2009), the proposed method is able to estimate the medullar ray angle for $Q$. petraea. Moreover, this method was designed considering a generic structure for the cross-section of the wood analysed, which is that represented by the synthetic image data, and it obtained promising results when applied to Q. petraea. For these reasons, this method could be applied to estimate the 
medullar ray angle in pieces of wood of other species that match the structure modelled by Fig. 2 .

The manual medullar ray angle measurement methodology employed in this article estimates an angle value for a piece of wood analysing the angle of several rays of this piece. Nevertheless, it does not take into account that these rays can vary their orientation along the piece, as can be observed in Fig. 9(c). On the other hand, the medullar ray angle estimation method proposed calculates an overall one for the ROI analysed in a given image. This means that, for some images such as Fig. 9(c), there is a significant error of $12.47^{\circ}$ despite the fact that the angle estimation seems to be good. This can be justified because the manual method of measuring the medullar ray angle does not describe the overall ROI, so does not consider all the different regions of the piece of wood.

The main advantages of the proposed method are two: its usefulness as a preprocessing step to automate other methods and its adaptability to be applied to different wood species. The first advantage is a characteristic of the method, which does not require any human interaction and can replace the manual steps of some dendro analysis methods. The second advantage is suggested by the generality of the method, which was designed and validated considering the synthetic images proposed in this article and which was successfully tested with Quercus petraea wood images. One disadvantage is that the accuracy could be not as good as expected with other species because of its generality. Nevertheless, in these cases the method could be improved by particularizing it to the wood species considered.

The proposed method could be applied as a prior stage of some dendro methods or some industrial applications in order to estimate features such as ring width in good conditions. Moreover, this method will also be useful for research , in order to consider the estimated angle as an interesting variable for wood-related models.

As previously mentioned, the objective of this article was to design and propose a general method to estimate the medullar ray angle for different wood species. Further work that was not considered in this article and could be done when implementing this method is the optimization of some of the stages of the method and the particularization to the specific wood species to be analysed. One is to employ the Radon transform to replace and optimize the image rotation substage and the projection calculation substage. Another optimization could be the reduction of the number of iterations of the fitness calculation stage by doing an initial search with low angle resolution considering the complete range of possible angles, and a second search with a high angle resolution for a reduced range of angles around the best candidate resulting from the initial search. As regards the particularization for a specific species of wood, preprocessing stages or additional or modified substages of the proposed method could be employed in order to adapt it to the particular anatomical characteristics of the species analysed and to improve the performance and robustness of the method.

Finally, to the best of the authors' knowledge, there are no other methods to estimate the medullar ray angle from the cross-section of pieces of any species of wood nor a similar procedure to estimate the orientation for other applications. As mentioned in the Introduction, other methods have been proposed by other authors to estimate the orientation of the objects from an image applied to other fields. Moreover, these methods employ the 2D-FFT or other techniques nonrelated to the Discrete Fourier Transform, but none of them proposed a procedure like that presented here.

\section{Conclusions}

An FFT-based method to estimate the medullar ray angle from the cross-section of a piece of wood was designed, implemented, and evaluated in this article. The results obtained suggest the suitability of the proposed method to estimate this parameter in pieces of wood sawn with 
different medullar ray angles and different distances to the pith of the log. Moreover, this method was validated with a set of images, obtaining a mean absolute estimation error and mean squared error of $5.91^{\circ}$ and $8.19^{\circ}$, respectively. The proposed method allows estimation of the direction of the best linear path to evaluate several wood ring features, which could be useful for several dendro analysis methods described in the literature. Using the angle estimated by the proposed method it will be possible to automate the initial task of those dendro analysis methods or some industrial procedures, eliminating the need for a technician to perform the task and reducing its processing time.

\section{References}

Balducci L, Cuny HE, Rathgeber CBK, et al (2016) Compensatory mechanisms mitigate the effect of warming and drought on wood formation. Plant, Cell Environ 39:1338-1352.

Bartens J, Grissino-Mayer HD, Day SD, Eric Wiseman P (2012) Evaluating the potential for dendrochronological analysis of live oak (Quercus virginiana Mill.) from the urban and rural environment—An explorative study. Dendrochronologia 30:15-21.

Bauwe A, Jurasinski G, Scharnweber T, et al (2016) Impact of climate change on tree-ring growth of scots pine, common beech and pedunculate Oak in northeastern Germany. IForest 9:111.

Bian Q, Chen SY, Liu YC (2013) A Rotation Based Sorting Method for the Feature Points Abstracted from Skew Calibration Image. Appl Mech Mater 427-429:1939-1943.

Camarero JJ, Olano JM, Parras A (2010) Plastic bimodal xylogenesis in conifers from continental Mediterranean climates. New Phytol 185:471-480.

Chaudhuri BB, Kundu P, Sarkar N (1993) Detection and gradation of oriented texture. Pattern Recognit Lett 14:147-153.

Deslauriers A, Rossi S, Anfodillo T, Saracino A (2008) Cambial phenology, wood formation and temperature thresholds in two contrasting years at high altitude in southern Italy. Tree Physiol 28:863-871.

Fernández MP, Norero A, Vera JR, Pérez E (2011) A functionalstructural model for radiata pine (Pinus radiata) focusing on tree architecture and wood quality. Ann Bot 108:1155-1178.

Feuillat F, Huber F, Keller (1992) Focus on: The concept of grain used for classification of oak staves (Quercus robur L., Quercus petraea Liebl.). Rev française d'oenologie 32:65-69.

Feuillat F, Keller R (1997) Variability of Oak Wood (Quercus robur L., Quercus petraea Liebl.) Anatomy Relating to Cask Properties. Am J Enol Vitic 48:502-508.

Fromm J (ed) (2013) Cellular Aspects of Wood Formation. Heidelberg, Germany.

García Esteban L, Guindeo Casasús A, Peraza Oramas C, de Palacios de Palacios P (2003) Wood and its anatomy: anomalies and defects. Ediciones Mundi-Prensa, Madrid, Spain.

Gartner H, Schweingruber FH (2013) Microscopic preparation techniques for stem analysis. Verlag-WSL, Birmensdorf, Switzerland.

Guillaume de Pracomtal MM, Teissier du Cros R, Monteau A-C (2014) Types of oak grain, wine élevage in barrel. Pract Winer Vineyard 64-69.

Haneca K, Katarina Cufar, Beeckman H (2009) Oaks, tree-rings and wooden cultural heritage: a review of the main characteristics and applications of oak dendrochronology in Europe. $\mathrm{J}$ Archaeol Sci 36:1-11. 
Hietz P (2011) A simple program to measure and analyse tree rings using Excel, $\mathrm{R}$ and SigmaScan. Dendrochronologia / Ist Ital di Dendrocronologia 29:245-250.

Hroš M, Vavrčík H (2014) Comparison of earlywood vessel variables in the wood of Quercus robur L. and Quercus petraea (Mattuschka) Liebl. growing at the same site. Dendrochronologia 32:284-289.

Josso B, Burton DR, Lalor MJ (2005) Texture orientation and anisotropy calculation by Fourier transform and Principal Component Analysis. Mech Syst Signal Process 19:1152-1161.

Kampe A, Magel E (2013) New Insights into Heartwood and Heartwood Formation. In: Fromm J (ed) Cellular Aspects of Wood Formation. Springer Berlin Heidelberg, Berlin, Heidelberg, pp 71-95

Lara W, Bravo F, Sierra CA (2015) measuRing: An R package to measure tree-ring widths from scanned images. Dendrochronologia 34:43-50.

Larson P (1969) Wood formation and the concept of wood quality. Yale Univ Sch For vol Bullet:54.

Plomion C, Leprovost G, Stokes A (2001) Wood Formation in Trees Wood Formation in Trees. Plant Physiol 127:1513-1523.

Romagnoli M, Cavalli D, Spinaa S (2014) Wood quality of chestnut: Relationship between ring width, specific gravity, and physical and mechanical properties. BioResources 9:11321147.

Rossi S, Deslauriers A, Anfodillo T (2006) Assessment of cambial activity and xylogenesis by microsampling tree species: An example at the Alpine timberline. IAWA J 27:383-394.

Seguin Moreau Napa Cooperage (2016) Coopering process. http://seguinmoreaunapa.com/resources/coopering-process/ (accessed on July 2017).

Van den Bulcke J, Wernersson ELG, Dierick M, et al (2014) 3D tree-ring analysis using helical X-ray tomography. Dendrochronologia 32:39-46.

Vivas N (1995) The notion of grain in cooperage. J des Sci Tech la Tonnellerie 1:17-32.

Zambal S, Palfinger W, Stöger M, Eitzinger C (2015) Accurate fibre orientation measurement for carbon fibre surfaces. Pattern recognition 48:3324-3332.

Zobel BJ, Buijtenen JP van (1989) Wood Variation: Its Causes and Control. Berlin Heidelberg, Germany 